\section{(6) OPEN ACCESS}

\title{
Single versus multiple-family intervention in childhood overweight-Finnmark Activity School: a randomised trial
}

\author{
Ane Kokkvoll, ${ }^{1}$ Sameline Grimsgaard, ${ }^{2,3}$ Rønnaug Ødegaard, ${ }^{4,5}$ Trond Flægstad, $^{6,7}$ \\ Inger Njølstad ${ }^{3}$
}

${ }^{1}$ Department of Paediatrics, Hammerfest Hospital, Hammerfest, Norway ${ }^{2}$ Clinical Research Department, University Hospital of North Norway, Tromsø, Norway ${ }^{3}$ Department of Community Medicine, Faculty of Health Sciences, University of Tromsø, Tromsø, Norway

${ }^{4}$ Department of Paediatrics, St Olavs Hospital, Trondheim, Norway

${ }^{5}$ Department of Laboratory Medicine, Children's and

Women's Health, Norwegian University of Science and Technology, Trondheim, Norway

${ }^{6}$ Department of Paediatrics, University Hospital of North Norway, Tromsø, Norway ${ }^{7}$ Faculty of Health Sciences, University of Tromsø, Tromsø, Norway

\section{Correspondence to}

Dr Ane Kokkvoll, Department of Paediatrics, Hammerfest Hospital, Sykehusveien, Hammerfest N-9600, Norway; ane.kokkvoll@helse-finnmark. no

Received 18 December 2012 Revised 27 September 2013 Accepted 9 November 2013 Published Online First 11 December 2013 Paediatric Research Group,

\section{ABSTRACT \\ Objective To compare a new comprehensive lifestyle programme performed in groups of families with overweight (included obese) children with a more conventional single-family programme. The study design and interim anthropometrical results after 12 months are} presented.

Design Altogether 97 overweight and obese children aged $6-12$ years with body mass index (BMI) corresponding to cut-off point $\geq 27.5$ in adults were included. Study participants were randomised to multiple-family intervention (MUFI) or single-family intervention (SIFI) in a parallel design. MUFI comprised a 3-day inpatient programme at the hospital with other families and a multidisciplinary team, follow-up visits in their hometown individually and in groups, organised physical activity twice weekly and a 4-day family camp after 6 months. SIFI comprised individual counselling by paediatric nurse, paediatric consultant and nutritionist at the hospital and follow-up by public health nurse in the community. Solution focused approach was applied in both interventions. Primary outcome measures were change in BMI kg/m² and BMI SD score (BMI SDS).

Results BMI increased by 0.37 units in the MUFI compared to 0.77 units in the SIFI $(p=0.18)$. BMI SDS decreased by 0.16 units in the MUFI group compared to 0.07 units in the SIFI group ( $p=0.07)$. Secondary endpoint waist circumference decreased $0.94 \mathrm{~cm}$ in the multiple-family group and increased $0.95 \mathrm{~cm}$ in the single-family group, $p=0.04$.

Conclusions Interim analysis after 12 months showed no between-group difference in terms of BMI or BMI SDS. The MUFI group had a significant decrease in waist circumference compared to the SIFI group.

The trial is registered at http://www.clinicaltrials.gov (NCT00872807)

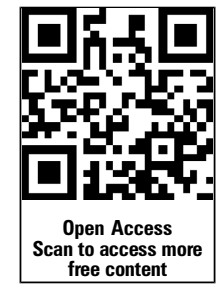

To cite: Kokkvoll $\mathrm{A}$, Grimsgaard S, Ødegaard R, et al. Arch Dis Child 2014;99:225-231.

\section{INTRODUCTION}

Being obese may have negative effects on physical and psychosocial health. ${ }^{1}$ Therefore, the worldwide increase in childhood overweight and obesity is of great concern. ${ }^{2}$ Those who are obese in late childhood, tend to stay obese as adults, ${ }^{3}$ and efforts should be made to stop weight gain in overweight and obese youngsters.

Standard hospital treatment of obese children has been reported to be ineffective, ${ }^{4}$ whereas lifestyle programmes may be effective after 6-12 months if the whole family is included and if the intervention consists of dietary, behavioural and physical activity components, according to the

\section{What is already known}

Standard hospital treatment for childhood obesity has been reported to be ineffective.

- Reviews evaluating child obesity interventions conclude that comprehensive treatment models appear effective, but underline that the knowledge base to inform treatment strategies is limited.

- Most childhood obesity programmes are performed in hospital settings and there is limited data on long-term effects (beyond 1 year).

\section{What this study adds}

A multidisciplinary solution focused obesity intervention performed in groups of families and in single families showed no between-group effect in body mass index after 12 months.

- Children allocated to multiple-family intervention had a significant decrease in waist circumference compared to the children allocated to single-family intervention.

- This trial will provide long-term results of a generally applicable treatment programme performed in a shared model across primary and specialised healthcare.

latest Cochrane review. ${ }^{5}$ Cognitive therapy, behaviour modification and family therapy are the most frequently used approaches to induce lifestyle changes. The review ${ }^{5}$ concluded that there is too limited quality data to consider one treatment programme better than others and called for long-term studies of obesity intervention in youngsters and cost-effective programmes for primary care.

Group intervention has appeared as a method of interest for childhood obesity treatment due to the possible dual effect of the group facilitator and interaction with group participants. ${ }^{6}$ However, few trials investigated the effectiveness of child obesity group intervention, and the results diverge. ${ }^{7-9}$ The prevalence of combined overweight and obesity among 6-year-old children in Finnmark County was $19 \%$ in $2007 .{ }^{10}$ The paediatric service at 
Hammerfest Hospital is the only one in a large rural region, and long travelling distances for referred patients stimulated new intervention strategies. In a pilot study involving hospital and community health workers, we experienced that intervention aiming at lifestyle changes in obese children had to take place in the municipality where the families live their daily lives. Parents also made us aware of the important provider-family relationship and our team became inspired by solution focused work. ${ }^{11}$

Based on our pilot study and in search for an effective obesity programme, we developed and tested a multidisciplinary intervention model to be used in groups of families. In this trial we compare the multiple-family intervention (MUFI) with a more conventional model of healthcare for individual families. This article describes the study design and interim anthropometrical results after 12 months.

\section{MATERIALS AND METHODS}

\section{Study design}

The 'Finnmark Activity School' is an ongoing randomised trial with two parallel arms. The family is the interventional unit and includes the child, parents and in some cases $(n=8)$, a sibling. Children are randomised to either single-family intervention (SIFI) or MUFI. The primary outcome is between-group differences in body mass index (BMI, $\mathrm{kg} / \mathrm{m}^{2}$ ) after 2 years. Secondary outcomes are between-group differences in physical activity, nutrition, and anthropometrical, metabolic and psychological measures. The trial is designed, conducted and reported in accordance with Consolidated Standards of Reporting Trials (CONSORT) guidelines. ${ }^{12}$ There has been no deviation from the study protocol other than recruiting in two cycles to obtain sufficient number of participants.

\section{Participants and settings}

The study started in 2009 at the Paediatric Department at Hammerfest Hospital in collaboration with the University Hospital of North Norway (UNN) and the University of Tromsø. Prior to enrolment, formal representatives of the hospital and each participating municipality signed a mutually binding agreement. The families were recruited through advertising and media coverage from six municipalities in Finnmark County (total population 73000 and mainly rural settlements) and one municipality in neighbouring Troms County (Tromsø city, 70000 inhabitants). Inclusion criteria were age $6-12$ years and BMI corresponding to adult $\mathrm{BMI} \geq 27.5 \mathrm{~kg} / \mathrm{m}^{2}$. The latter was calculated as the middle between the two international cut-off points defining overweight and obesity in children, ${ }^{13}$ by age and gender. Exclusion criteria were diseases incompatible with ordinary physical activity and psychosocial disorders incompatible with group interaction.

Staff at Hammerfest Hospital conducted the study, collected data and organised courses for all healthcare providers involved. The intervention period will be completed by November 2013 .

\section{Randomisation and concealment}

Following eligibility assessment and written informed consent, the study nurse phoned the central randomisation unit at UNN for group allocation. Randomisation lists were computer generated (block randomisation, random block size) and stratified by age (6-9 and 10-12 years). Personnel involved in the randomisation did not take any further part in the study.

\section{Single-family intervention}

Families allocated to SIFI met at the hospital outpatient clinic. The children underwent baseline anthropometric measurements, followed by 30 -min counselling by a paediatric study nurse.
Subsequently, a paediatric consultant performed a clinical interview and examination $(30 \mathrm{~min})$ and outlined definite aims towards the next consultation. All families met with a nutritionist after 1-2 months. They were followed up by a public health nurse in their own municipality at $1,2,5,8,10,15$ and 18 months from baseline, and at the hospital by a paediatric nurse and a paediatric consultant at 3,12, 24 and 36 months.

\section{Multiple-family intervention}

Families allocated to MUFI underwent anthropometric measurements and individual counselling identical to those of the SIFI programme. Additional elements were: (1) a 3-day inpatient programme at the Paediatric Department focusing on physical activity and healthy food, (2) group sessions with other families and a multidisciplinary hospital team (paediatric and psychiatric nurse, paediatric consultant, nutritionist, physiotherapist, coach and clinical educationalist), (3) municipality follow-up including individual (30 $\mathrm{min})$ and groupwise counselling $(1 \mathrm{~h})$ with a public health nurse, (4) group-based physical activities twice weekly (each session lasting $1 \mathrm{~h}$, organised by coach and by parents, respectively), (5) family participation in a 4-day camp after 4-6 months. Table 1 summarises the two intervention programmes.

\section{Staff and methodology}

Both interventions were performed in a shared model across primary and specialised healthcare. Principles from Solution-Focused Brief Therapy and Standardised Obesity Family Therapy were applied in addition to elements from motivational interviewing. ${ }^{11} 1415$ Counselling based on the families' own resources aiming at increasing physical activity, reducing sedentary activity and increasing consumption of healthy food according to national guidelines was the main approach in both intervention arms.

Public health nurses, nutritionists, paediatric nurses and paediatric consultants were involved in both interventions,

Table 1 Characteristics of the two intervention programmesFinnmark Activity School

\begin{tabular}{|c|c|c|}
\hline $\begin{array}{l}\text { Content of the } \\
\text { intervention }\end{array}$ & $\begin{array}{l}\text { Single-family } \\
\text { intervention }\end{array}$ & $\begin{array}{l}\text { Multiple-family } \\
\text { intervention }\end{array}$ \\
\hline Who is the target & Parents and child & Parents and child \\
\hline $\begin{array}{l}\text { Responsible for } \\
\text { the intervention }\end{array}$ & Community and hospital & Community and hospital \\
\hline Start & $\begin{array}{l}\text { Outpatient clinic stay for } \\
1 \text { day }\end{array}$ & $\begin{array}{l}\text { Inpatient clinic stay for } \\
3 \text { days }\end{array}$ \\
\hline $\begin{array}{l}\text { Who delivers the } \\
\text { intervention }\end{array}$ & $\begin{array}{l}\text { Project nurse, paediatrician } \\
\text { and nutritionist at the } \\
\text { hospital. Public health } \\
\text { nurse in the municipality. }\end{array}$ & $\begin{array}{l}\text { Multidisciplinary team at the } \\
\text { hospital. Public health nurse, } \\
\text { physiotherapist and coach in } \\
\text { the municipality. }\end{array}$ \\
\hline How & Every family individually & $\begin{array}{l}\text { Families individually and in } \\
\text { groups }\end{array}$ \\
\hline $\begin{array}{l}\text { Physical activity } \\
\text { for children }\end{array}$ & Not arranged & $2 \mathrm{~h}$ a week in groups \\
\hline Camp for families & No camp & $\begin{array}{l}4 \text { days } 6-8 \text { months from } \\
\text { baseline }\end{array}$ \\
\hline $\begin{array}{l}\text { Solution focused } \\
\text { counselling }\end{array}$ & Yes & Yes \\
\hline $\begin{array}{l}\text { Follow-up } \\
\text { intervals }\end{array}$ & $\begin{array}{l}1-3,5,7,10,12,18,24 \\
36 \text { months }\end{array}$ & $\begin{array}{l}\text { Equal intervals as the } \\
\text { single-family group }\end{array}$ \\
\hline $\begin{array}{l}\text { Hours of contact } \\
\text { first } 12 \text { months }\end{array}$ & $8 \mathrm{~h}$ & $36 \mathrm{~h}$ \\
\hline $\begin{array}{l}\text { Organised } \\
\text { physical activity } \\
\text { first } 12 \text { months }\end{array}$ & $\mathrm{Oh}$ & $38 \mathrm{~h}$ \\
\hline
\end{tabular}




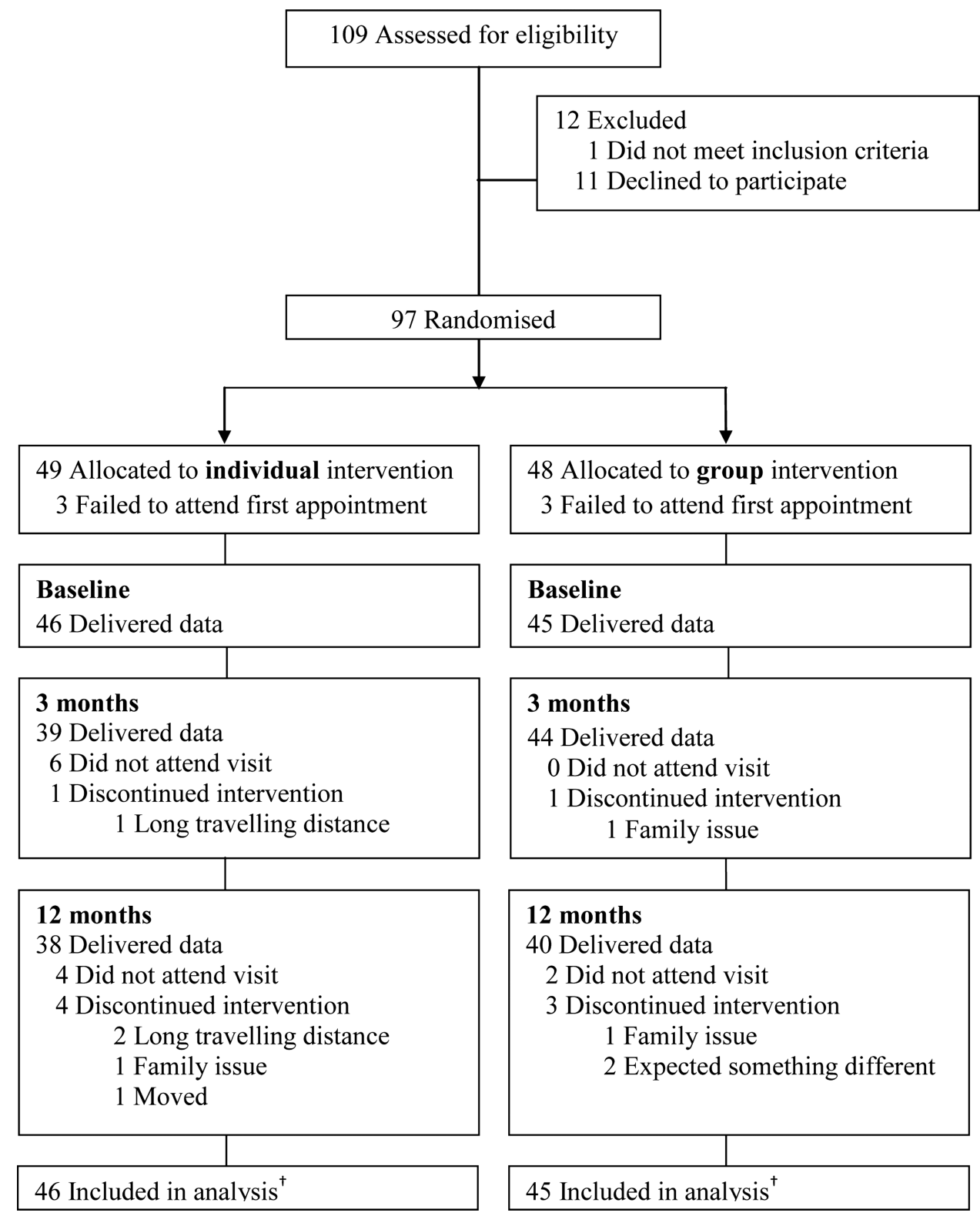

Figure 1 Flow of participants* through first year of treatment-Finnmark Activity School. *Siblings are not included in the analysis. tLongitudinal analyses include all available data from every subject through withdrawal or study completion.

whereas clinical educationalist, physiotherapist and coach were only involved in the group intervention arm.

Study personnel participated in four courses (1.5 days each) covering causes and consequences of childhood obesity, as well as nutrition, physical activity, introduction to family therapy and a brief solution focused method. ${ }^{14}$

\section{Outcomes and blinding}

Data were collected during prescheduled hospital visits at baseline and at 3, 12, 24 and 36 months of follow-up and included anthropometric measurements, blood samples, bioelectrical impedance analysis (BIA), clinical examinations and questionnaires. BMI and BMI SD score (BMI SDS) were the primary outcomes.

Height was measured to the nearest $0.1 \mathrm{~cm}$ with a portable Harpenden Stadiometer and weight to the nearest $0.1 \mathrm{~kg}$ with a digital Seca portable scale by nurses blinded to group allocation. All children were measured between 08:00 and 11:00 am, wearing underwear and a shirt. BMI $\mathrm{kg} / \mathrm{m}^{2}$ were calculated and
BMI SDS extracted from an obesity calculator based on British reference data. ${ }^{1617}$ Two study nurses unblinded to group allocation measured waist circumference, triceps skinfold thickness and body composition in all children. Waist circumference was measured at the midpoint between the lowest rib and the top of the iliac crest with a measuring tape at the end of normal expiration. Skinfold was picked up on the posterior part of $\mathrm{m}$. triceps by the thumb and forefinger and measured with a Holtain Tanner/Whitehouse Skinfold Caliper. ${ }^{18}$ If interassessor measurements deviated $>1.0 \mathrm{~cm}$ in waist circumference and $>1.0 \mathrm{~mm}$ in skinfold, the two measurements were repeated once, if the child admitted to it. Mean value of the two observations was used in all analyses. Fat and lean body mass was obtained by BIA (Tanita Body Compositon Analyzer BC-418) with the child in standing position. Clinical examination included scaling pubes stages by pubic hair growth. ${ }^{19} 20$

Precautions were taken to keep primary outcome assessors blinded to group allocation. Nurses who measured height and weight were neither employed at the Paediatric Department nor 
involved in the intervention in other respects. Families were instructed not to talk about the intervention with the primary outcome assessors and these nurses were instructed to report whether blinding was no longer present.

\section{Sample size and power}

The study was powered to detect a between-group difference in mean change of $0.5 \mathrm{~kg} / \mathrm{m}^{2}$ BMI with SD of 0.8 from baseline to 2 years with two-sided $\alpha$-level of $0.05 \%$ and $80 \%$ power. A sample size of 50 families in each group was needed given an expected withdrawal of $20 \%$.

\section{METHODS}

Differences between intervention groups at baseline were assessed by two-sample $t$ test and Pearson $\chi^{2}$ tests. All data were analysed by the intention-to-treat principle. Linear mixed models $^{21}$ were used to compare time trends in BMI (and secondary anthropometrical outcomes) between the two groups over three time points. The independent variables were: group, time (as two indicator variables) and cross product terms between each indicator variable of time with group. A significant group-by-time interaction indicated different time trends between the intervention groups.

In secondary analyses, we adjusted for random differences at baseline. All analyses were performed using Stata V.12.1 (StataCorp 4905 Lakeway Drive College Station, Texas, USA). Two-sided value $(p<0.05)$ was considered statistically significant.

The families gave written informed consent signed by parents and all children $\geq 12$ years. The Norwegian Social Science Data Services consented to the privacy protection in the study.

\section{RESULTS}

\section{Flow of participants and baseline characteristics}

A total of 127 enquiries by phone resulted in 109 meetings for eligibility assessment. Following assessment, 97 (89\%) families consented and were randomised, 11 declined to participate and one did not meet the inclusion criteria. Median interval between randomisation and baseline measurements was 50 days. Six participants (three in each group) withdrew from the study before start (baseline). Subject retention from inclusion to 12 months was $80 \%$. Thus, we obtained baseline data for 91 children, 3-month follow-up data for 83 children and 12-month follow-up data for 78 children. There was no difference in attendance between the two intervention groups and no adverse effects were reported. Figure 1 shows participant flow from recruitment to 12 -month follow-up. Baseline data showed that $77 \%$ of the children were obese and everyone had a waist circumference above the 95 th centile according to British reference values. $^{22}$ No differences between intervention groups were detected in baseline variables (table 2).

\section{Outcome data}

Mean BMI increased in both intervention groups during the first 12 months of study but less so in the MUFI group (0.37) than in the SIFI group (0.77) (figure 2). There was no difference in BMI change between the intervention groups $\left(0.40 \mathrm{~kg} / \mathrm{m}^{2}\right)$ (95\% CI -0.99 to 0.18 ) (table 3). Adjustment for baseline values did not change this result. Mean decrease in BMI SDS was 0.16 units in the MUFI group and 0.07 units in the SIFI group, $\mathrm{p}=0.07$ (table 3 ).

Waist circumference decreased in the MUFI group $(-0.94 \mathrm{~cm})$ and increased in the SIFI group $(+0.95), p=0.036$ (table 3, figure 3). No between-group difference was observed for
Table 2 Baseline characteristics of study participants according to intervention group-Finnmark Activity School

\begin{tabular}{|c|c|c|c|}
\hline Characteristics & $\begin{array}{l}\text { Single-family } \\
\text { intervention } \\
n=46\end{array}$ & $\begin{array}{l}\text { Multiple-family } \\
\text { intervention } \\
\mathrm{n}=45\end{array}$ & $\begin{array}{l}\text { Between-group } \\
\text { p value }\end{array}$ \\
\hline Age in years & $10.5 \pm 1.7$ & $10.1 \pm 1.7$ & 0.24 \\
\hline Female/male & $22 / 24$ & $27 / 18$ & 0.24 \\
\hline $\begin{array}{l}\text { Tanner puberty } \\
\geq 2 \text { at baseline* }\end{array}$ & $14(31)$ & $14(31)$ & \\
\hline BMI $\left(\mathrm{kg} / \mathrm{m}^{2}\right)$ & $27.6 \pm 4.3$ & $26.9 \pm 4.2$ & 0.42 \\
\hline BMI SDSt & $2.81 \pm 0.60$ & $2.76 \pm 0.58$ & 0.70 \\
\hline $\begin{array}{l}\text { Obesity at } \\
\text { baseline } \neq\end{array}$ & $36(78)$ & $34(76)$ & 0.76 \\
\hline $\begin{array}{l}\text { Waist } \\
\text { circumference } \\
(\mathrm{cm})\end{array}$ & $89.2 \pm 11.9$ & $87.9 \pm 12.0$ & 0.62 \\
\hline Body fat $(\%) \S$ & $35.8 \pm 5.2$ & $35.3 \pm 5.0$ & 0.66 \\
\hline $\begin{array}{l}\text { Triceps skinfold } \\
(\mathrm{mm})\end{array}$ & $26.1 \pm 4.3$ & $25.4 \pm 4.5$ & 0.47 \\
\hline $\begin{array}{l}\text { Mother BMI }(\mathrm{kg} / \\
\left.\mathrm{m}^{2}\right)(\mathrm{n})\end{array}$ & $29.8 \pm 6.8(43)$ & $29.9 \pm 8.1(41)$ & 0.95 \\
\hline $\begin{array}{l}\text { Father BMI }(\mathrm{kg} / \\
\left.\mathrm{m}^{2}\right)(\mathrm{n})\end{array}$ & $29.5 \pm 4.3(20)$ & $30.3 \pm 5.5(21)$ & 0.63 \\
\hline \multicolumn{4}{|c|}{$\begin{array}{l}\text { Baseline characteristics are presented as mean } \pm \text { SD for continuous variables and } \\
\text { number (per cent) for binary variables. } \\
{ }^{*} \text { Pubes development according to Tanner. }{ }^{19} 20 \\
\text { †BMI SDS according to British reference. }{ }^{17} \\
\text { †Obesity according to Cole } 2000 .^{13} \\
\text { §Body composition measured by bioelectrical impedance analysis. } \\
\text { BMI, body mass index. }\end{array}$} \\
\hline
\end{tabular}

skinfold thickness or body fat at 12 months (table 3 ). In pooled data from both intervention groups, BMI SDS decreased significantly $(-0.12$ BMI SDS units $(95 \%$ CI -0.17 to -0.07$)$ ) (data not shown).

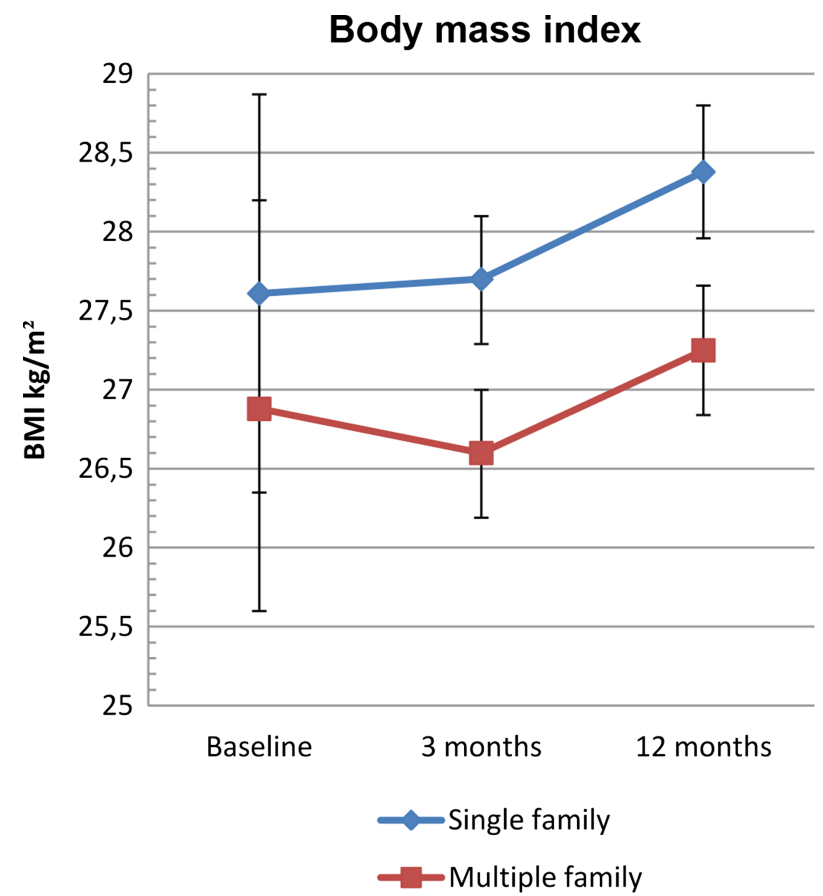

Figure 2 Body mass index (BMI) $\mathrm{kg} / \mathrm{m}^{2}$ from baseline to 12 months by intervention group-Finnmark Activity School. Mean $(95 \% \mathrm{Cl})$ changes in BMI from baseline to 12-month follow-up by intervention group. 
Table 3 Changes in body mass index (BMI) and secondary anthropometrical outcomes by treatment group-Finnmark Activity School

\begin{tabular}{|c|c|c|c|c|}
\hline & \multicolumn{2}{|c|}{ Change $(95 \% \mathrm{Cls})$ at follow-up } & \multirow{2}{*}{$\begin{array}{l}\text { Between-group difference } \\
\text { Coefficient }(95 \% \mathrm{Cl})\end{array}$} & \multirow{2}{*}{$\begin{array}{l}\text { p Value } \neq \\
\text { Group-by-time }\end{array}$} \\
\hline & Single-family & Multiple-family & & \\
\hline \multicolumn{5}{|c|}{ BMI crude $\mathrm{kg} / \mathrm{m}^{2}$} \\
\hline 3 months & $0.09(-0.32$ to 0.49$)$ & $-0.26(-0.67$ to 0.14$)$ & $-0.35(-0.92$ to 0.22$)$ & 0.228 \\
\hline 12 months & 0.77 (0.35 to 1.19$)$ & $0.37(-0.04$ to 0.78$)$ & $-0.40(-0.99$ to 0.18$)$ & 0.179 \\
\hline \multicolumn{5}{|c|}{$\mathrm{BMI}$ adjusted $\mathrm{kg} / \mathrm{m}^{2 *}$} \\
\hline 3 months & $0.07(-0.32$ to 0.47$)$ & $-0.27(-0.67$ to 0.12$)$ & $-0.35(-0.90$ to 0.21$)$ & 0.221 \\
\hline 12 months & 0.77 (0.37 to 1.17$)$ & $0.38(-0.02$ to 0.78$)$ & $-0.39(-0.96$ to 0.17$)$ & 0.173 \\
\hline \multicolumn{5}{|l|}{ BMI SDSt } \\
\hline 3 months & $-0.05(-0.12$ to 0.01$)$ & $-0.13(-0.20$ to -0.07$)$ & $-0.08(-0.17$ to 0.01$)$ & 0.097 \\
\hline 12 months & $-0.07(-0.14$ to -0.01$)$ & $-0.16(-0.23$ to -0.09$)$ & $-0.09(-0.18$ to 0.01$)$ & 0.068 \\
\hline \multicolumn{5}{|c|}{ Waist circumference } \\
\hline 3 months & $-0.03(-1.26$ to 1.20$)$ & $-1.45(-2.67$ to -0.23$)$ & $-1.42(-3.15$ to 0.31$)$ & 0.108 \\
\hline 12 months & $0.95(-0.31$ to 2.22$)$ & $-0.94(-2.18$ to 0.3$)$ & $-1.89(-3.67$ to -0.12$)$ & 0.036 \\
\hline \multicolumn{5}{|l|}{ Skinfold } \\
\hline 3 months & $-1.52(-2.32$ to -0.73$)$ & $-3.05(-3.83$ to -2.56$)$ & $-1.52(-2.64$ to -0.40$)$ & 0.008 \\
\hline 12 months & $-3.95(-4.76$ to -3.13$)$ & $-4.5(-5.3$ to -3.70$)$ & $-0.55(-1.70$ to 0.59$)$ & 0.342 \\
\hline \multicolumn{5}{|l|}{ Body fat $\%$} \\
\hline 3 months & $0.5(-0.50$ to 1.5$)$ & $-0.3(-1.29$ to 0.68$)$ & $-0.81(-2.21$ to 0.60$)$ & 0.261 \\
\hline 12 months & 0.39 (0.64 to 1.42$)$ & $-0.02(-1.03$ to 0.98$)$ & $-0.41(-1.85$ to 1.02$)$ & 0.574 \\
\hline
\end{tabular}

\section{Waist circumference}

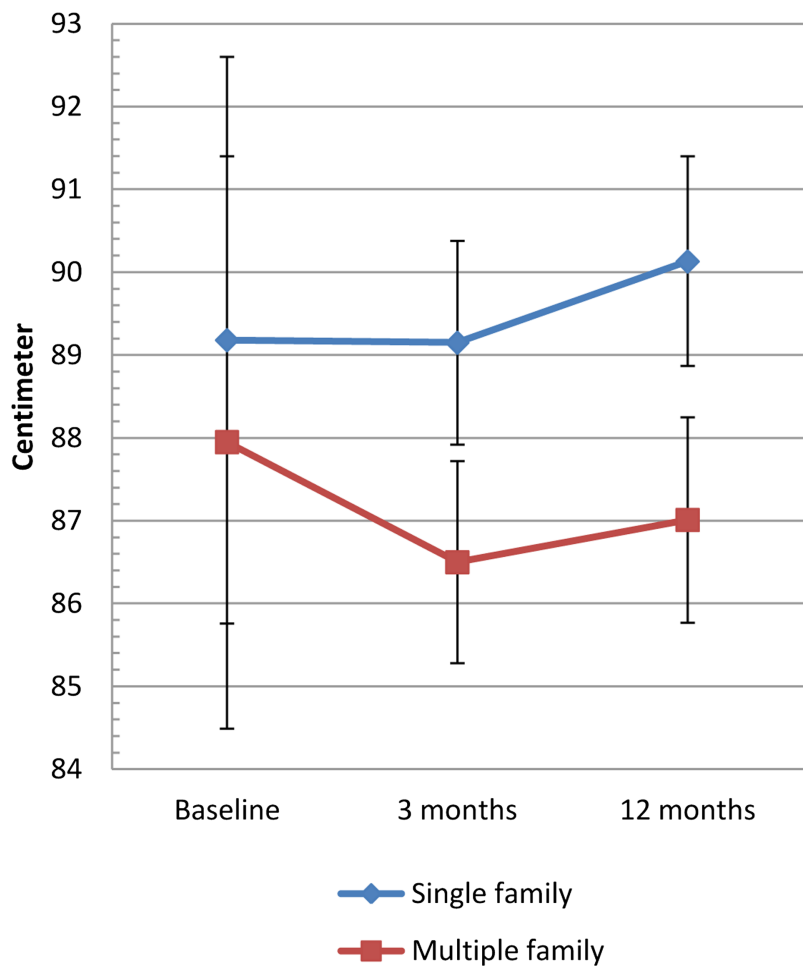

Figure 3 Waist circumferences from baseline to 12 months by intervention group-Finnmark Activity School. Mean ( $95 \% \mathrm{Cl}$ ) changes in waist circumference from baseline to 12-month follow-up by intervention group.

\section{DISCUSSION}

Interim results from the present trial showed no difference between intervention groups in terms of BMI, but a small significant difference in waist circumference in favour of MUFI after 12 months.

Group-based intensive weight management programmes targeting children and youths have shown significant between-group effects on BMI compared to traditional weight management. $^{7} \quad 8 \quad 23 \quad 24$ In contrast, there was no difference between intervention arms in some group-based medium-to-low intensive programmes. ${ }^{9} 2526$ One review of obesity interventions for primary healthcare pointed to a positive relationship between hours of contact and treatment effect. ${ }^{27}$ In the present study, increasing the hours of contact might possibly contribute to an increased treatment effect, but would also imply increased use of resources, and thus make the programme less feasible for primary healthcare. A qualitative study emphasised the tailoring of advice to each family in child obesity treatment, ${ }^{28}$ and one could speculate whether the MUFI approach may dilute the effect of individually based consultations.

The solution focused approach was applied in both groups with a higher intensity in the MUFI group, but so far this higher intensity does not seem to affect weight change. This finding is in accordance with earlier studies showing effectiveness of this approach after limited number of sessions. ${ }^{14}$

There is a strong association between excess abdominal fat and cardiovascular risk factors, ${ }^{29}$ but few weight management programmes reported on this outcome in children. ${ }^{9} 26$ 30-32 One intervention model focusing on diet and physical activity reported a significant between-group difference in waist circumference at 6 months. $^{23}$ The authors argued that waist 
circumference is not dependent on lean body mass and is therefore a more appropriate outcome when studying effects of physical activity. The organised physical activity component in the MUFI programme could contribute to the small group-by-time effect in waist circumference in the present study. There were, however, no corresponding between-group differences in body composition outcomes at 12 months.

\section{Strengths and limitations}

The randomised design, blinding of the primary outcome assessors and the moderate withdrawal comprise the main strengths of this study. On the other hand, variability in BMI change was larger than expected and contributed to a decrease in study power.

The overweight inclusion criterion corresponded to adult $\mathrm{BMI} \geq 27.5 \mathrm{~kg} / \mathrm{m}^{2} .{ }^{13}$ This criterion is below the International Obesity Task Force obesity definition, which corresponds to adult BMI 30, but was a pragmatic choice to recruit high-risk overweight and obese children into the study. This strategy provided sufficient inclusion from the participating municipalities, while excluding children only slightly overweight.

The nurses who measured waist circumference, skinfold and BIA were not blinded to group allocation. Measurement of waist circumference is difficult to obtain and may be hampered by measurement error. ${ }^{23}$ Giving priority to quality control and continuity, we chose two experienced paediatric nurses to obtain the above-mentioned measurements, although they were involved in the study conduct and therefore unblinded to group allocation. Waist circumference is considered an objective measure, but it may be argued that this approach could bias study results.

\section{Relation to other studies}

The pooled modest reduction in BMI SDS corresponds to results from intervention trials performed mainly in hospital settings ${ }^{5}{ }^{33-35}$ and programmes considered feasible or performed in primary care. ${ }^{2324} 273236-38$ Heterogeneity of study populations and outcome parameters makes it difficult to compare effectiveness across studies.

\section{CONCLUSION}

There was no difference in change in the primary outcomes BMI and BMI SDS between the MUFI approach and the SIFI approach after 1 year. There was a small between-group effect in the secondary outcome waist circumference in favour of the MUFI. Results after 2 years of follow-up are needed to draw further conclusions.

Acknowledgements We want to thank all the participating families, all personnel involved in the Finnmark Activity School trial and the municipality of Kautokeino, Alta, Vadsø, Kirkenes, Lebesby, Hammerfest and Tromsø. We also want to thank the families participating in the pilot project, Professor Lars Bo Andersen University of Southern Denmark, Professor John A Rønning, University of Tromsø, participants in the early Activity School Reference Group, representatives from Finnmark County Authority, County Governor of Finnmark and Finnmark Sport Council who all contributed with valuable support in the development of this project. The authors thank Professor Tom Wilsgaard for advice and quality assurance of the statistical analysis in this paper.

Contributors AK designed the study, conducted the study, analysed and interpreted the data and wrote the original manuscript. SG designed the study, involved in conducting the study, data interpretation and edited the manuscript. RØ contributed to the design of the study, data interpretation and edited the manuscript. TF designed the study and was involved in conducting the study, data interpretation and edited the manuscript. IN designed the study and was involved in conducting the study, interpretation of data and editing the manuscript in addition to statistical advices. All authors have read and approved the final manuscript.
Funding The trial has been supported by Finnmark Hospital Trust, Northern Norway Regional Health Authority, Norwegian Foundation for Health and Rehabilitation and The Norwegian Directorate of Health. Contributions have also been made by the University of Tromsø, the Ministry of Health and Care Services, SpareBank 1 Nord-Norge and Odd Berg Fund.

Competing interests None.

Ethics approval The Regional Committee for Medical and Health Research Ethics approved the study.

Provenance and peer review Not commissioned; externally peer reviewed.

Open Access This is an Open Access article distributed in accordance with the Creative Commons Attribution Non Commercial (CC BY-NC 3.0) license, which permits others to distribute, remix, adapt, build upon this work non-commercially, and license their derivative works on different terms, provided the original work is properly cited and the use is non-commercial. See: http://creativecommons.org/ licenses/by-nc/3.0/

\section{REFERENCES}

1 Reilly JJ. Descriptive epidemiology and health consequences of childhood obesity. Best Pract Res Clin Endocrinol Metab 2005; 19:327-41.

2 Wang Y, Lobstein T. Worldwide trends in childhood overweight and obesity. Int J Pediatr Obes 2006;1:11-25.

3 Singh AS, Mulder C, Twisk JW, et al. Tracking of childhood overweight into adulthood: a systematic review of the literature. Obes Rev 2008;9:474-88.

4 Quattrin T, Liu E, Shaw N, et al. Obese children who are referred to the pediatric endocrinologist: characteristics and outcome. Pediatrics 2005;115:348-51.

5 Oude Luttikhuis $\mathrm{H}$, Baur $\mathrm{L}$, Jansen $\mathrm{H}$, et al. Interventions for treating obesity in children. Cochrane Database Syst Rev 2009:CD001872.

6 Nowicka P, Savoye M, Fisher PA. Which psychological method is most effective for group treatment? Int J Pediatr Obes 2011;6(Suppl 1):70-3.

7 Savoye $M$, Nowicka $P$, Shaw $M$, et al. Long-term results of an obesity program in an ethnically diverse pediatric population. Pediatrics 2011;127:402-10.

8 Nowicka P, Hoglund P, Pietrobelli A, et al. Family Weight School treatment: 1-year results in obese adolescents. Int J Pediatr Obes 2008;3:141-7.

9 Kalavainen M, Korppi M, Nuutinen 0 . Long-term efficacy of group-based treatment for childhood obesity compared with routinely given individual counselling. Int J Obes (Lond) 2011;35:530-3.

10 Kokkvoll A, Jeppesen $E$, Juliusson PB, et al. High prevalence of overweight and obesity among 6-year-old children in Finnmark County, North Norway. Acta Paediatr 2012;101:924-28.

11 De Shazer S, Berg IK, Lipchik E, et al. Brief therapy: focused solution development. Fam Process 1986;25:207-21.

12 Moher D, Hopewell S, Schulz KF, et al. CONSORT 2010 explanation and elaboration: updated guidelines for reporting parallel group randomised trials. BMJ 2010:340:c869.

13 Cole TJ, Bellizzi MC, Flegal KM, et al. Establishing a standard definition for child overweight and obesity worldwide: international survey. BMJ 2000;320:1240-3.

14 Nowicka P, Flodmark CE. Family therapy as a model for treating childhood obesity: useful tools for clinicians. Clin Child Psychol Psychiatry 2011;16:129-45.

15 Miller WR, Rollnick S. Ten things that motivational interviewing is not. Behav Cogn Psychother 2009;37:129-40.

16 Institute B-HIN. Child obesity calculator using British 1990 growth reference data. Secondary Child obesity calculator using British 1990 growth reference data. http://www.phsim.man.ac.uk

17 Cole TJ, Freeman JV, Preece MA. Body mass index reference curves for the UK, 1990. Arch Dis Child 1995:73:25-9.

18 Juliusson PB, Roelants M, Eide GE, et al. Overweight and obesity in Norwegian children: secular trends in weight-for-height and skinfolds. Acta Paediatr 2007;96:1333-7

19 Marshall WA, Tanner JM. Variations in pattern of pubertal changes in girls. Arch Dis Child 1969:44:291-303.

20 Marshall WA, Tanner JM. Variations in the pattern of pubertal changes in boys. Arch Dis Child 1970:45:13-23.

21 Twisk JW, de Vente W. The analysis of randomised controlled trial data with more than one follow-up measurement. A comparison between different approaches. Eur J Epidemiol 2008;23:655-60.

22 McCarthy HD, Jarrett KV, Crawley HF. The development of waist circumference percentiles in British children aged 5.0-16.9 y. Eur J Clin Nutr 2001;55:902-7.

23 Sacher PM, Kolotourou M, Chadwick PM, et al. Randomized controlled trial of the MEND program: a family-based community intervention for childhood obesity. Obesity (Silver Spring) 2010;18(Suppl 1):S62-8.

24 DeBar LL, Stevens VJ, Perrin N, et al. A primary care-based, multicomponent lifestyle intervention for overweight adolescent females. Pediatrics 2012;129: e611-20.

25 Kalarchian MA, Levine MD, Arslanian SA, et al. Family-based treatment of severe pediatric obesity: randomized, controlled trial. Pediatrics 2009:124:1060-8. 
26 Croker H, Viner RM, Nicholls D, et al. Family-based behavioural treatment of childhood obesity in a UK National Health Service setting: randomized controlled trial. Int J Obes (Lond) 2012:36:16-26.

27 Whitlock EP, O'Connor EA, Williams SB, et al. Effectiveness of weight management interventions in children: a targeted systematic review for the USPSTF. Pediatrics 2010;125:e396-418

28 Banks J, Cramer $\mathrm{H}$, Sharp DJ, et al. Identifying families' reasons for engaging or not engaging with childhood obesity services: A qualitative study. J Child Health Care 2013.

29 McCarthy HD. Body fat measurements in children as predictors for the metabolic syndrome: focus on waist circumference. Proc Nutr Soc 2006;65:385-92.

30 Hughes AR, Stewart L, Chapple J, et al. Randomized, controlled trial of a best-practice individualized behavioral program for treatment of childhood overweight: Scottish Childhood Overweight Treatment Trial (SCOTT). Pediatrics 2008; 121:e539-46.

31 Collins CE, Okely AD, Morgan PJ, et al. Parent diet modification, child activity, or both in obese children: an RCT. Pediatrics 2011;127:619-27.
32 Wake M, Lycett $\mathrm{K}$, Clifford SA, et al. Shared care obesity management in 3-10-year-old children: 12 month outcomes of HopSCOTCH randomised trial. BMJ 2013;346:f3092.

33 McGovern L, Johnson JN, Paulo R, et al. Clinical review: treatment of pediatric obesity: a systematic review and meta-analysis of randomized trials. J Clin Endocrinol Metab 2008:93:4600-5.

34 Canoy D, Bundred P. Obesity in children. Clin Evid (Online) 2011;2011.

35 Ho M, Garnett SP, Baur L, et al. Effectiveness of lifestyle interventions in child obesity: systematic review with meta-analysis. Pediatrics 2012;130:e1647-71.

36 Wake M, Baur LA, Gerner B, et al. Outcomes and costs of primary care surveillance and intervention for overweight or obese children: the LEAP 2 randomised controlled trial. BMJ 2009;339:b3308.

37 Janicke DM, Sallinen BJ, Perri MG, et al. Comparison of parent-only vs family-based interventions for overweight children in underserved rural settings: outcomes from project STORY. Arch Pediatr Adolesc Med 2008:162:1119-25.

38 Taveras EM, Gortmaker SL, Hohman KH, et al. Randomized controlled trial to improve primary care to prevent and manage childhood obesity: the High Five for Kids study. Arch Pediatr Adolesc Med 2011;165:714-22. 